https://doi.org/10.3126/pragya.v7i1.35108

\title{
Knowledge and Practice of Fertility Behavior among the Musahar Women in Nepal
}

\begin{abstract}
Musahars are the Terai Dalit community living in low land; basically Southern part of Nepal and the most deprived and marginalized groups. The aim of this study is to identify the nexus between knowledge, practices and its relation to fertility behavior and adoption of family planning methods. Fertility is a way through which human beings biologically substitute themselves in order to continue their existence on earth. This study reveals that married women and those who have children had relatively better knowledge about fertility behavior and methods of family planning than newly married and unmarried females. Similarly, adolescent mothers consistently had low level of use in each of the contraceptive methods mentioned by the respondents during the study. In addition, the study shows that many of older mothers enjoyed more support from their husbands compared to adolescent mothers when it comes to decision on whether fertility related issues and use method of family planning. This information suggests that interpersonal communication between husbands and wives on the use of contraceptive was relatively higher among older mothers compared with adolescent mothers. There is a huge impact of explanatory variables of the research topic like age, ethnicity, education, marital status, employment status, knowledge of family planning, number of children and attitude on the use of modern contraceptives etc. to the use of contraceptives.
\end{abstract}

Key words: knowledge, practice, fertility behavior, birth control measures and Mushahar women.

\section{Introduction}

Anthropological perspectives on birth are concerned with the context, variety, and complexity of reproductive life, modes of caring for a newborn infant, and cultural factors including rules for behavior that are learned, shared, and transmitted within families and cultural groups. Reproductive behavior is determined by the socio-cultural factors (Davis \& Blake, 1956). There is cross-cultural variation among societies during these universal human processes. Because birth and recruitment to society are important to all human groups, customs and rules surround fertility behavior in all societies (Newman, 2001).

Different scholars have formulated concepts on the fertility behavior. Moral constraint helps to control fertility (Malthus, 1986), Marx argued that population size is determined by mode of production. Dumont (1890, cited by Leridon, 2015) argued that 
social progress controls the fertility. The concept of fertility behavior is depending on respective society, culture and traditions. Natural environment is also responsible for creating the concept of fertility behavior. It is not similar among the all-human societies. Fertility behavior refers to the childbearing patterns of women or couples, with special reference to the number of births, the timing of births, and associated reproductive behaviors such as union formation (including marriage and co-habitation) and contraceptive behavior (http://www.sciencedirect.com).

Fertility behavior is the process of giving birth, which is interacted with the ambient environment and the environment is different in different societies within the biological limitation of human fertility. Several social, cultural, psychological as well as economic and political factors are found to operate and these are responsible for determining the levels and differentials of fertility (Bhende and Kanitkar, 2008).

\section{Brief overview to Mushahar}

The Musahar community is an ethnic group that exists within the Dalit, or 'untouchable,' caste system and is one of the most disadvantaged and marginalized groups in the world. Chaudhary (2008) argued that Musahars are fully backward, Dalit, untouchable, highly marginalized, excluded group, very poor and landlessness. Likewise Giri (2012) also claimed that Musahars were included untouchables category of caste system without specific ritual based caste occupation. Being socio-politically weakest and economically resource less group of the Tarai, Musahars deployed various strategies of livelihood.

According to Choubey (2008) Musahars were originally a Munda-speaking huntergatherer group living on the Chota Nagpur Plateau. Around 1650-1700, they migrated off the plateau to the eastern Gangetic Plain. They became agricultural laborers to landlords who spoke Indo-Aryan languages, and in order to communicate with them and gain social status, they learnt their landlords' languages. The stigma of their tribal roots resulted in their placement at the lowest end of the caste hierarchy.

Musahar is one of the most significant ethnic groups as well as Tarai Dalit (so called untouchable) group of Nepal. Untouchability is the significant character of the traditional Hindu caste system. As other groups of the country, fertility condition of Musahar people depends on their socio-economic, socio-cultural and demographic environments. Musahars are socio-economically and politically deprived ethnic group of Nepal who are not involved in national mainstream.

In the case of Tarai Dalit, Musahar is marginalized group. They normally tend to marry at an early age, which explains the lack of education along with social and economic deprivation. Most of the Musahar boy and girl marry before teen age and some of them get 
married in late teen which results in a larger span of marital and child bearing period with substantially a higher fertility period. Additionally, prevailing high infant and child mortality and contraceptive prevalence is also important component of fertility behavior. Due to limited use and lack of knowledge of contraceptive method, Musahar community has higher rate of fertility.

There are various causes, which are directly or indirectly associated with fertility behavior of Musahar community, exclusively Musahar women. The responsible causes are level of knowledge, economic status as well as family activities and women, social and cultural taboos and norms, and empowering people to use the contraceptive method. Basically, Musahar couples hesitate to consult the health post and other health centers for their sexual health issues, which also include the proper way of using contraceptives. Lack of knowledge and feeling shy to discuss about it are the major causes for using contraceptives in a wrong way. Some of them think that using contraceptives may cause a serious health problem in future. Hence, if only this community becomes aware about the proper method and the consequences of using contraceptives then the problems of high amount of childbirth could be controlled.

\section{Statement of the Problem}

Demographic transition theory states that fertility rate is comparatively high among the poor, traditional and non-industrial societies because of high mortality, lack of opportunities for individuals, less advancement and higher economic value of children. These all changes with modernization or urban industrialism and individuals, once their viewpoints become reoriented use of the new opportunities (Caldwell, 1993). Likewise demographers and social scientists even today are in search of systematic theory which would provide explanation for change in fertility levels and differentials infertility and which would also serve as a basis for predicting future fertility trends. This gap in the knowledge of demographic phenomena continues despite the efforts made by several social scientists with various theories of fertility (Bhende and Kanitkar, 2008).

Fertility behavior is also affected by 'status of women'. The status refers to women's overall position in society. The rights and obligations of women also indicate their social, economic, and demographic behavior therefore the status of women has been frequently considered as one of the influencing variables in the study of the fertility behavior. The United Nations defined that the socio-economic status of women as labor, student, wife and mother. It also includes the empowerment and prestige connected with the women's right and duties. Women's status is related to the extent of women's command over the social and economic matters in household and extra household circumstances have great influence on human life (UN, 1973). 
Fertility has declined over the last decades from 5.1 children per women in 1991 to 4.6 children per women in 1996 and further to 4.1 in 2001. The increased use of contraceptives and also changed methods together favors of temporary method is largely responsible for his/her decline. Since there exists a strong relationship between contraceptive use and fertility established relationship (Pathak, 2011).

Except some developed countries, population growth has posed a great challenge and consequently facing the problems of high social population that might be barriers for the overall development of the countries. Nepal, being an exception of this the mortality is decreasing rapidly but fertility is not decreasing in same pace as a result of which the population is increasing day by day. The population which was 18.5 million in 1991 has increased to 26 million in 20011 (CBS, 2011).

Only the reduced level of infant and child mortality may be a strongly governing factor for fertility reduction in a largely uneducated agrarian society. Socio-economic and cultural mechanisms play their active roles to persist high fertility and also have negative impact on both fertility and mortality. Caldwell's proportion is that, children usually have great chances of survival when they are born to an uneducated mother than to a highly educated mother in a largely uneducated society (Tuladhar, 1989). This proves that literacy is another important determining factor of fertility.

Das (2000) stated that high economic value of children along with socio-economic tradition of favoring son, low status of women in the society; low literacy rate and lack of use of birth control measures as well as high infant mortality are some of the significant factors that contribute to high demand for children and high fertility in the country. Therefore, generally a society takes a large period of time to transfer from high fertility to low fertility. Above statements generate the research question about knowledge and perception on fertility of Musahar women.

The study of human fertility is of prime importance in population studies. The human fertility is responsible for the biological replacement and maintenance of the human species, since every society substitutes itself and grows through the process of childbirth. Therefore, in context of population dynamics it is important to note that fertility is one of the major remedial forces that aids in overcoming mortality. Contrary to this, an increased level of fertility more than desired might result in population explosion. Nepal is a developing country where many ethnic and minority groups are well known for their rich culture, practice and tradition. Fertility culture differs by ethnic groups and their cultural practices. This is primarily because of the marked cultural diversity of Nepal wherein the factors that affect the fertility status vary from one population to another. Studies have 
reported that there are copious factors that affect the fertility pattern of a population, either directly or indirectly.

Anthropological demography began to expand in earlier only after 1970 with the convergence of these trends (Fricke, 1986). The trend, criticizes the family planning programs and it challenges the assumptions of classical demographic transition theory by showing that colonial contact and capitalization of indigenous population can actually accelerate population growth by increasing the demand for children (Fricke, 1986). Another, but most one is the ecological anthropology possessed a long-standing interest in population that activated with these other developments. Ecological analysis has always focused on subsistence behavior within and environmental context and demographic variables were always seen as a part of the relationship. Fricke agrees with Stewardian ecological analysis that, needed to determine how much exploitative behavior influenced other aspects of culture, including demography, settlement patterns, ownership structures, land tenure and land use. Fricke also applied the Boserupian model, as population growth gave rise to agricultural intensification. Agrees with Steward and Boserup, Fricke mentions the role of population variable in social change. He also adopts the Caldwellian model in which Caldwell argues the population transitions depend on the socio-culture matrix of fertility behavior (Fricke, 1986).

Age at first menstruation, age at marriage, age at first conception, and number of conceptions and live births are some of the biological factors that determine fertility. In contrast to this, the educational status, occupation status, household per capita annual income, family type, and use of birth control measures are the social factors that affect the fertility pattern of a population. The present study tries to investigate the knowledge and practices of fertility behavior among an endogamous Hindu caste group, the Musahar. So, this research helps to find out the gap between them, which is the core theme of the research. The core research problem problematized here is what is the knowledge and practices of fertility behavior among the Mushahar women of Nepal. This research tries to set up following research question-

- What is the Knowledge and practice on fertility behavior among the Musahar women?

- What are the socio-cultural factors, which affect the knowledge and practices of fertility behavior of Musahar women

These are the common research questions, which helped to gather information.

These questions facilitated the researcher to make frame of research to conduct research clearly. 


\section{Objective and Methods}

The main objective of this study is to investigate the knowledge and practice on fertility behavior among the Musahar women. To fulfill the objective following research methods were adopted properly. This study was based on primary source and basically qualitative as well as quantitative in nature. The simple statistical tools eg., table, percentage were also used to explore and document the collected information. In the present study, different villages of ward number one, which are densely populated by Musahar community in Siraha district, Province No. 2 were purposively selected. For the required data collection a pretested interview schedule was framed and employed. Household survey was conducted among the total of 70 women who were married for a long time. In the process of data collection, selected women respondents were familiarized with the purpose of the study. Prior to initiating the interview, informed written consent was taken from the participants. In order to maintain secrecy and confidentiality of the study prescheduled interviews were conducted in the isolation. Information regarding the reproductive history of the respondent, namely, age at menstruation, age at marriage, age at first conception, age at last conception, and age at menopause, number of conceptions, and number of live births were collected from the participants. Likewise, use of contraceptive and method of contraceptive use, information source of family planning method was also asked. Besides this, the data relating to educational status, and birth control measure were also collected from the participants.

\section{Result and Discussions}

\section{Knowledge and Practice of Fertility Behavior among the Musahar Women}

In the present study, certain measures of fertility are utilized in order to understand the fertility trends of the Musahar people. However, general fertility rate, general marital fertility rate, and the child women ratio of the studied community are higher than the other neighboring caste and ethnic group. This section deals about socio-demographic characters of Musahar women and knowledge, practice of fertility behavior of Musahar women and other aspects which are directly associated with the study.

\section{Socio demographic characters of Musahar women}

Socio-demographic background includes age, marital status and marriage at age, religion as well as economic variables of studied population who were women. Family status also determines the status of women, which ultimately determines the fertility, family planning, and status of studied women.

\section{Educational status of Mushahar women}

Education plays a vital role to determine fertility behavior and family size. 
According to CBS (2011) Nepal's literacy rate is only 54. 1 percent for the sex, and only 42.8 percent female are literate which is very low. Occupation is another determining factor of fertility. Woman's independence is reflected in terms of education attainment and professional careers, which are the two major factors that determine the family size of the woman in a household. Mostly, educated women marry late because of their educational and professional obligations and are also conscious of having a limited family size. It is an important variable for fertility behavior. The numbers of conceptions and live births were found to be significantly higher among the illiterate women than the literate. Table 1 tries to explain the impact of education on fertility behavior of Musahar women. According to the following table among the total (70) studied Musahar women 25 are literate and rest of 45 are illiterate which comprises 35.7 and 64.3 respectively. This shows that the highest numbers of Musahar women are illiterate.

\section{Table 1: Educational status of Musahar women}

\begin{tabular}{lcc}
\hline \multicolumn{1}{c}{ Literacy status } & number & Percentage \\
\hline Literate & 25 & 35.7 \\
Illiterate & 45 & 64.3 \\
\hline Total & 70 & 100.0
\end{tabular}

Source: Field Survey, 2019.

\section{Age at marriage}

Marriage is one of the most important social institutions for living a comprehensive and gratified life. Marriage is recognized as an important structural element of the society. It unites the two opposite sexes in order to satisfy the individual's social, cultural and biological needs 'Marriage is a union between a man and a woman such that children born to the women are recognized legitimate offspring of both parents' (Royal Anthropological Institute 1951, P. 110, cited in Gough, 2000, P. 237). Among the Musahar people marriage takes place in the early age of the girls and boys, which leads to long term socio economic consequences including higher fertility. From the field study, it is observed that early marriage resulted more number of children. Traditionally marriage usually takes place at very early age in Nepal. Some studies have showed that an increasing in female age at marriage contributes to the reduction in fertility. This also true in case of Nepal where the inverse relationship between age at marriage and facility has been observed (Chhetry, 1993).

The age at marriage and age at first conception can be due to the social motivation that is experienced by a woman in a Musahar community following marriage. Musahar people follow the strict mating patterns with community endogamy and clan exogamy. Musahar community is also a patriarchal as other neighbor tribal, ethnic and caste groups, 
so after marriage a woman is absorbed into the household of her in-laws as wherein she takes the role of her mother-in-law's helper. It was observed that a newly married woman often sleeps with her mother-in-law in the hind portion of house designated for women and children. Consequently, little interaction takes place between the husband and the wife since the house has a gender specific social space. The cohabitation between newly married couple is not possible because there is no specially designated place for the couple. The following table shows the age at marriage of studied Musahar women.

Table 2: Age at marriage of Musahar women

\begin{tabular}{ccc}
\hline Age at marriage & Number of women & Percentage \\
\hline Below 15 years & 22 & 31.4 \\
15-19 years & 40 & 57.2 \\
20-24 years & 6 & 8.6 \\
Above 24 years & 2 & 2.8 \\
\hline
\end{tabular}

Source: Field Study, 2019.

The above table shows the distribution of the Musahar women who were included in the study based on their age at marriage. Among the total number of studied women, which is 70, 40 women or 57.2 percent women were married at the age of 15-19 years. The lowest number is 2 among the 70 respondents who got married at the age of above 24 years. This data indicates that usually Musahar girls get married at the teenage that shows the trend of early marriage. Table 2 further expresses about the preferred age at marriage for the presently studied population is 15-19 years. The age at marriage was found to be quite close to the age of menarche. This is an indication towards the strong cultural constraints that are prevailing in the studied community, which compels the girls to get married immediately following menarche. From Table 2, it is clear that majority of the women are getting married before the age of 19 years (57.2\%) signifying that child marriage is quite prevalent in Musahar community. Further, the age at marriage is also affecting the number of live births in the community.

\section{Knowledge and practices of Musahar women on fertility}

Birth control measures have important implications on the fertility behavior of a woman. In the present study it is seen that the use of birth control measures does not have any influence on the fertility behavior of the Musahar women. Most of the studies on fertility knowledge have been conducted in women only. Since, men play a major role in childbearing decisions and timing, it is important to assess their level of understanding and knowledge of factors affecting fertility (Danilk and Koert, 2013).

While awareness of family planning is almost universal among Nepali men and women; there is significant variation between different caste/ethnic groups in terms of 
practice. Other than the Tarai/Madhesi high castes, the highest level of use of modern method of contraceptives is among the Tarai Janajati (65 percent) while the lowest is among the Muslims (17 percent). Dalits and Janajatis of the hilly region also fall below the country's average contraceptive prevalence level (44 percent) with usage rates of just 35 percent and 37 percent, respectively. The Tarai / Madhes origin groups have higher average usage rates than Hill/Mountain groups (Bennett, Dahal and Govindasamy, 2008). The studied women have knowledge about family planning methods but they do not use properly due to some constraints. The Musahar women have the knowledge but do not put it in practice.

According demographic transition theory, there are four stages of transition. In Musahar community women's fertility behavior shows the early stage 2, early transition phase. In this stage, birth rate high and population grow rapidly.

\section{Use of family planning method}

Birth control measures have important implications on the fertility behavior of a woman. In the present study it is seen that the use of birth control measures does not have any influence on the fertility behavior of the Musahar women. The use of family planning method reduces the fertility. It can also manage the rapid growth of population but it is because of lack of knowledge of the contraceptive method, educational attainment and low economic status that family planning has not been put into practice. The following table presents the use pattern and method of birth control measures by Musahar women respectively.

\section{Table 3: Use and method of contraceptives by Musahar women}

\begin{tabular}{ccc}
\hline Use of contraceptives & number of women & percentage \\
\hline Yes & 26 & 37.5 \\
No & 44 & 62.5 \\
\hline Total & 70 & 100.0 \\
\hline Method of contraceptive use & & \\
\hline Permanent & 18 & 69.3 \\
Temporary & 8 & 30.7 \\
\hline Total & 26 & 100.0
\end{tabular}

Source: field study, 2019. 
Table 3 shows the use and method of contraceptive or birth control measures. According to table 3 total number and percentage of users and non-users of contraceptives for birth control is mentioned further. 26 respondents who occupy 37.5 percent of total studied population were using contraceptives and 44 women with 62.5 percent of the total studied population were not using any type of contraceptive. The researcher was informed that the main reason of using contraceptives was the awareness about usefulness of contraceptives among the Musahar women who are little bit educated. Accordingly they wanted to have small sized family. Rest of the respondents who covered 62.5 percent under the age of 16 and above the age of 40 years are not found using contraceptives due to lack of awareness about the contraceptives. Likewise, methods of contraceptive use for birth control are also explained in table 3. According to the table 18 women out of 26, which is 69.3 percent, are using the permanent method of contraception for birth control. And at the same time 8 respondents, which represent only 30.7 percent of the total interviewed women, use temporary contraceptive method.

\section{Sources of information and reason for not using birth control measures}

There are various sources by which the studied Musahar women know about different family planning methods either permanent or temporary. The main sources of information and reason for not using birth control measures are shown in the table.

Table 4: Sources of information and reason for not using birth control measures

\begin{tabular}{lcc}
\hline Source of information & number of women & Percentage \\
\hline Friends & 10 & 14.3 \\
Husband & 9 & 12.9 \\
Health worker & 8 & 11.4 \\
Radio, television & 28 & 40.0 \\
Social networks & 15 & 21.4 \\
\hline Total & 70 & 100.0 \\
\hline Reasons for not using & & \\
birth control measures & & \\
& 5 & \\
\hline Lack of depth knowledge & 9 & 20.4 \\
Fear of side effects & 24 & 54.5 \\
Because of husband & 1 & 2.3 \\
Poverty & 5 & 11.4 \\
Unavailability & 44 & 100.0
\end{tabular}

Source: Field Survey, 2019.

Table 4 attempts to deliver the data about sources of information about family 
planning methods/birth control methods and causes of not using the contraceptives. Among the 70 Mushahar women 28 individuals reported that radio and television are the main source of information about birth control measures, which is 40 percent, the highest number and followed by lowest 11.4 percent is through health workers. Likewise the other sources of information are friends 14.3 percent, husband 12.9 percent, and social network 21.4 percent respectively. This study also found various reasons for not using the birth control measures. Main reasons for not using the contraceptive are- lack of proper and correct knowledge about contraceptive uses, fear of side effect of contraceptives, because of husband unwillingness, poverty and unavailability of easy access of contraceptives. Table 4 shows that 54.5 percent women could not use birth control measures because of their own husband's rejection which is the largest number among all. Similarly, other reasons for not using birth control measures are- lack of in depth knowledge 11.4 percent, fear of side effects 20.4, poverty 2.3 percent and 11.4 percent respondents could not use family planning devices due to unavailability.

\section{Gender preference and distribution of children}

Among the social factors that affect the fertility status of a population, preference for male child is one of the most important factors. The preference for a male child among the parents in the Nepali society is one of the most important reasons leading to the explosion of population in the society. Many researches have shown that son preference is the main cause of high fertility throughout all human society including Nepal. It is the main character of patriarchy where son is given more preference than daughter. This is also prevalent among the Musahar community. Among the Musahar, gender preference and fertility is directly related. As a result of this there are more boy children than girl child. The following table presents the gender preference of Musahar women and existing number of Musahar children based on their sex.

Table 5: Gender preference and distribution of children

\begin{tabular}{ccc}
\hline Gender preference & Number of women & Percentage \\
\hline Son & 46 & 65.7 \\
Daughter & 9 & 12.8 \\
No preference & 15 & 21.5 \\
\hline Total & 70 & 100.0 \\
\hline Sex & Number of children & Percentage \\
\hline Male & 125 & 58.1 \\
Female & 90 & 41.9 \\
\hline Total & 215 & 100.0 \\
\hline
\end{tabular}

Source: Field Study, 2019. 
Table 5 tries to present gender preference of Musahar women. Most of the studied women that is 65.7 percent prefer male child and 21.5 percent studied women have no preference for child sex, which comprises second position. The lowest preference goes to female child that occupied only 12.8 percent. This is relatable to table 4 that articulate about the total number of Musahar children in the study area. According to table, there are 125 male and 90 are female children that comprises 58.1 and 41.9 percent respectively.

\section{Conclusions}

The study further reveals that among small proportion of women that were currently using at least a method of contraceptive; rely on instruction from their husbands/partners before they can adopt any method. In addition the study shows that many of mothers enjoyed more support from their husbands compared to among newly married girls when it comes to decision on whether to use a method of family planning. This information suggests that interpersonal communication between husbands and wives on the use of contraception was relatively higher among mothers compared with newly married in the study area. It should be noted that inter-spousal communication and agreement among spouses is one of the factors that can bring about rapid fertility transition to any given society or community.

In summary, findings in this study show that knowledge of contraceptive methods is gradually increasing among women in childbearing age, but the proportion of women using modern or efficient methods of family planning is comparatively low in the study area. In addition, it is essential to note that the knowledge, ever used and current use of contraceptive methods is generally low among just married women compared with older mothers in the study area.

It is found from the study that the impact of explanatory variables of the research topic like age, ethnicity, immigration status, education, marital status, employment status, knowledge of family planning, number of children and attitude towards modern contraceptives etc. to the use of contraceptives. Therefore it is fitted these variables into a binary logistic regression model with the contraceptive use as dependent variable.

\section{References}

Bennett, L., D.R Dahal \& Govindasamy (2008). Caste, ethnic and regional identity in Nepal. Further Analysis of the 2006 Nepal Demographic and Health Survey, September 2008.

Bhende, A.A. T. Kanitkar. (2008). Principles of population studies. Himalayan Publishing House.

Caldwell, J. (1993). Theory of intergenerational wealth low. Liege Belgium: Belgium Publishing House.

Chaudhry, J. K. (2008). Landless and its Impact in the life of Musahar: A study of 
Madheshi Dalit people at Pothiyahi VDC in Rautahat District Nepal. Research Report.

Chhetri, R.B. (1993). A biography of Dalit related studies in Nepal. Kathmandu: Martin Chautari, Kathmandu, Nepal.

Chaubey, G. (2008), “Language Shift by Indigenous Population: A model Genetic Study in South Asia”. International Journal of Human Genetics.

Daniluk, J.C.\& E. Koert (2013). The other side of the fertility coin: a comparison of childless men's and women's knowledge of fertility and assisted reproductive technology. Fertil Steril; 99(3): 839-46.

Das, A. (2000). Fertility behavior of women of Narayani Nepal. Khabar Butwal.

Davis, Kingsley and Judith Blake (1956). Social Structure and Fertility: An analytical framework. Economic Development and Social Change, 4(3): 211-235.

Fricke, Tom E., (1986), Himalayan Households; Tamang Demography and Social Processes, Ann Arbor, Mitchigan, UMI Research Press.

Giri, M. (2012). Politico Economic History of Marginalization and Change among the Musahars of East-Central Tarai. Contributions to Nepalese Studies, 39, 69-94.

Gough, E. Kathleen (2000), “ The Nayars and the definitions of marriage”. In Oberoi P. (Ed.) Family, Kinship and Marriage in India, Oxford University press, Pp. 237256.

Leridon., Henri (2015). The Development of fertility theories: A multidisciplinary endeavor, Population 70 (2), 309-348.

Newman, L.F. (2001). In international encyclopedia of the Social \& Behavioral Sciences.

Pathak, D.R. (2011). Bibliography on Nepal women. Kathmandu: Martin Chautari.

Tuladhar, J.M. (1989). Social Development. American Journal of Sociology, vol.9, no.4.

United Nation. (1973). The determinants and consequences of population trend. Department of Social Affairs Vol.2. 